\title{
Tertiary Survey Performance in a Regional Trauma Hospital Without a Dedicated Trauma Service
}

\author{
Gerben B. Keijzers • Don Campbell • Jeffrey Hooper • \\ Nerolie Bost $\cdot$ Julia Crilly $\cdot$ Michael Craig Steele • \\ Blake Eddington $\cdot$ Leo M. G. Geeraedts Jr.
}

Published online: 18 August 2011

(c) Société Internationale de Chirurgie 2011

\begin{abstract}
Background Initial management of trauma patients is focused on identifying life- and limb-threatening injuries and may lead to missed injuries. A tertiary survey can minimise the number and effect of missed injuries and involves a physical re-examination and review of all investigations within $24 \mathrm{~h}$ of admission. There is little information on current practice of tertiary survey performance in hospitals without a dedicated trauma service. We aimed to determine the rate of tertiary survey performance and the detail of documentation as well as the baseline rate of missed injuries.

Methods We performed a retrospective, descriptive study of all multitrauma patients who presented to an Australian level II regional trauma centre without a dedicated trauma
\end{abstract}

\footnotetext{
G. B. Keijzers

Emergency Department, Gold Coast Health Service District,

Gold Coast, QLD, Australia

G. B. Keijzers - M. C. Steele

Faculty of Health Sciences and Medicine, Bond University,

Gold Coast, QLD, Australia

e-mail: misteele@bond.edu.au

G. B. Keijzers ( $\square)$

Emergency Department, Gold Coast Hospital,

108 Nerang Street, Southport, QLD 4215, Australia

e-mail: gerben_keijzers@health.qld.gov.au

D. Campbell $\cdot$ J. Hooper $\cdot$ N. Bost

Emergency Department, Gold Coast Hospital,

108 Nerang Street, Southport, QLD 4225, Australia

e-mail: Don_Campbell@health.qld.gov.au

J. Hooper

e-mail: Jeffrey_Hooper@health.qld.gov.au

N. Bost

e-mail: Nerolie_Bost@health.qld.gov.au
}

service between May 2008 and February 2009. A medical records review was conducted to determine tertiary survey performance and missed injury rate.

Results Of 252 included trauma patients, $20 \%(n=51)$ had a tertiary survey performed. A total of nine missed injuries were detected in eight patients $(3.2 \%)$. Of the multiple components of the tertiary survey, most were poorly documented. Documentation was more comprehensive in the subgroup of patients who did have a formal tertiary survey.

Conclusions Tertiary survey performance was poor, as indicated by low documentation rates. The baseline missed injury rate was comparable to previous that of retrospective studies, although in this study an underestimation of true missed injury rates is likely. Implementing a formal, institutional tertiary survey may lead to improved tertiary

J. Crilly

Emergency Department Clinical Network, Gold Coast Hospital,

108 Nerang Street, Southport, QLD 4225, Australia

e-mail: Julia_Crilly@ health.qld.gov.au

J. Crilly

Research Centre for Clinical and Community Practice

Innovation, Griffith University, Gold Coast, QLD 4222,

Australia

B. Eddington

Emergency Department, The Tweed Heads Hospital,

Tweed Heads, NSW, Australia

e-mail: blakee@exemail.com

L. M. G. Geeraedts Jr.

Department of Surgery, VU University Medical Centre, P.O. Box 7057, 1007 MB Amsterdam, The Netherlands e-mail: 1.geeraedts@vumc.nl 
survey performance and documentation and therefore improved trauma care in hospitals without a dedicated trauma service.

\section{Introduction}

Assessment and management of multitrauma patients in the Emergency Department (ED) are time-critical and complex. All life- and limb-threatening injuries must be identified quickly while not missing any other injuries. Furthermore, an altered level of consciousness (due to central nervous system injury, intoxication, or sedation), a distracting injury, or need for emergent surgery may result in an incomplete initial examination, leading to undetected injuries. These missed injuries can cause extensive morbidity [1-12] and mortality [3, 5-7, 13, 14]. The standardized primary and secondary surveys of trauma patients have been shown to miss injuries at a rate that varies from 1.2 to $65 \%[1-11]$.

Because of the potential for missed injuries, a tertiary survey (TS) should follow the emergency care (including emergency surgery or interventional radiology). The term "tertiary survey" was first coined by Enderson et al. [1]. It is a comprehensive general physical re-examination and review of all investigations, including diagnostic imaging and blood results, within $24 \mathrm{~h}[6,9,10]$, and again when the patient is conscious, cooperative, and walking $[1,6,11]$.

Three retrospective studies in a setting with a dedicated trauma service reported missed injury rates from 1.2 to $4 \%$ [3-5], but it is unclear from the literature the missed injury rates that occur in hospitals without a dedicated trauma service. Our concern is that in such a setting, the use and documentation of a tertiary survey in trauma patients may be inconsistent, leading to more missed injuries.

This aims of this study were to (1) determine tertiary survey performance by investigating the rate and detail of tertiary survey documentation and (2) determine the baseline rate of missed injuries in admitted trauma patients in an institution that does not have a dedicated trauma service.

\section{Materials and methods}

\section{Design and setting}

This is a retrospective, descriptive study of all multitrauma patients who presented to the Gold Coast Hospital between May 2008 and February 2009. The Gold Coast Hospital (Queensland, Australia) is a teaching hospital with 570 beds and the Emergency Department had 67,000 presentations in 2009 , of which $0.7 \%$ were multitrauma patients. It is the designated level II [15] regional trauma hospital for the area and covers all major specialties, excluding cardiothoracic surgery and burns. There is currently no dedicated trauma service or formalized process for review of trauma patients who are admitted. Patients are currently managed on the ward at the discretion of the admitting general or subspecialty surgical consultant and team (registrar, one or two residents, and one intern) and by the intensive care team during any stay in the ICU. Which admitting team member performs the patient review (including tertiary survey) and the frequency and detail of this review is judged by the admitting team. Consultations from other specialties are requested at the discretion of the admitting team. The local Health District Human Research Ethics Committee approved this study.

\section{Patients}

All admitted trauma patients were identified using the Emergency Department Information System (EDIS) and the hospital information system (HBCIS). The accuracy of the resultant database of patients was cross-checked with the Queensland Trauma Registry (QTR).

Patients were included in the study if they were 16 years old or older and were admitted for at least $24 \mathrm{~h}$, AND they met any of the four following criteria: (1) injuries in two or more body regions, (2) a high-impact mechanism (highspeed motor vehicle collision, pedestrian versus car, fall $>1.5 \mathrm{~m}$ ), (3) chest or abdominal injuries, or (4) a fractured neck of the femur and under the age of 65 years. The medical records of the included 252 patients were reviewed.

\section{Data collection}

A dedicated research assistant reviewed the medical records of all included patients. Data collection included demographic variables, data on the ED stay, and hospital inpatient admission. Data related to the ED admission included mechanism of injury, Australian Triage Scale (ATS) category [16], and Glasgow Coma Scale (GCS) on arrival. If no GCS was documented but the patient was noted to be "alert," this was coded as a GCS of 15. The QTR provided the Injury Severity Score (ISS) [17] scores for our data set.

Data collection from the medical records focused on whether a formal TS was performed during admission. We noted the documentation rate for all components of the TS (re-examination, laboratory tests, and diagnostic imaging). Provisional reports of advanced imaging by radiologists were not classed as part of the TS; however, who reviewed the diagnostic imaging as part of the TS was noted. We defined a formal TS as "performed" when (at least) the re-examination component of the TS was documented 
Table 1 Definitions of formal tertiary survey performance and missed injury

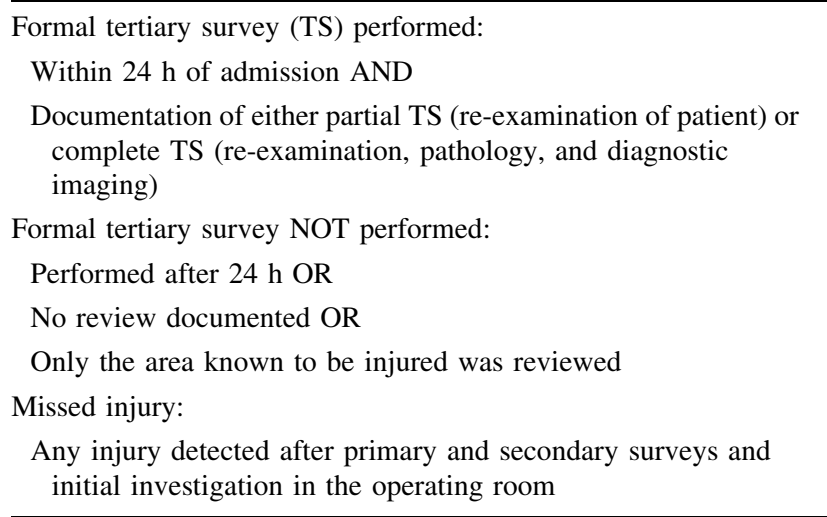

within $24 \mathrm{~h}$ of admission (Table 1). A TS was defined as "not performed" if there was no documentation of a TS and specifically if there was no documented review outside the area known to be injured. When a TS was not performed, data were collected on which parts of the examination were documented. If a patient was admitted under more than one team, we used the most extensive review for data collection. Data collection took place without the knowledge of the inpatient team(s) performing the reviews. A missed injury was defined as an injury that was not detected on the primary and the secondary survey and on the initial investigation in the operating room. Data on all in-hospital missed injuries were collected, including any resultant management.

\section{Statistical analysis}

De-identified data taken from all completed data collection sheets were collated using Excel spreadsheet software (Microsoft Corp., Redmond, WA, USA) and was coded prior to transfer to SPSS v17.0 software (SPSS Inc., Chicago, IL, USA) for statistical analysis. Before analysis, all variables were reviewed for accuracy of data entry, missing values, and outliers. For continuous variables, we used an independent $t$-test and analysis of variance (ANOVA) to compare demographic groups. For categorical variables, the $\chi^{2}$ test was used to compare differences in proportions. A $P$ value of 0.05 or less was deemed statistically significant.

\section{Results}

The baseline characteristics of the 252 patients are summarized in Table 2. The patients had a mean age of 35 years (SD 16) and 79\% were male. The average ISS was 13 (SD 9.8), with a quarter of patients admitted to the ICU.
Table 2 Characteristics of the study population

\begin{tabular}{|c|c|c|c|}
\hline Demographics $^{\mathrm{a}}$ & $\begin{array}{l}\text { Total } \\
(n=252)\end{array}$ & $\begin{array}{l}\text { Tertiary } \\
\text { survey } \\
\text { performed } \\
(n=51)\end{array}$ & $\begin{array}{l}\text { No tertiary } \\
\text { survey } \\
\text { performed } \\
(n=201)\end{array}$ \\
\hline Age (years) & $35.2(16)$ & $36.7(18)$ & $34.8(15)$ \\
\hline Male & 199 (79) & $40(78)$ & 159 (79) \\
\hline \multicolumn{4}{|l|}{ Australian triage scale } \\
\hline 1 & $64(25)$ & $29(57)$ & $35(17)^{* *}$ \\
\hline 2 & $111(44)$ & $19(37)$ & $92(46)$ \\
\hline 3 & $68(27)$ & $3(6)$ & $65(32)$ \\
\hline 4 & $9(4)$ & $0(0)$ & $9(4)$ \\
\hline ISS Score & $13.0(10)$ & $23.0(12.4)$ & $10.4(6.9)^{* *}$ \\
\hline ISS $>15$ & $74(30)$ & $37(73)$ & $37(18)^{* *}$ \\
\hline GCS $<15$ & $69(28)$ & $27(53)$ & $42(21)^{* *}$ \\
\hline \multicolumn{4}{|l|}{ Mechanism of injury } \\
\hline MVA, high speed & $32(13)$ & $12(24)$ & $20(10)^{*}$ \\
\hline MVA, moderate speed & $25(10)$ & $4(8)$ & $21(10)$ \\
\hline MBA & $57(23)$ & $9(18)$ & $48(24)$ \\
\hline Fall from height $>1.5 \mathrm{~m}$ & $46(18)$ & $8(16)$ & 38 (19) \\
\hline Pedestrian vs. car & $22(9)$ & $9(18)$ & $13(6)^{*}$ \\
\hline Other mechanism & $70(28)$ & $9(18)$ & $61(30)$ \\
\hline \multicolumn{4}{|l|}{ Disposition } \\
\hline Surgical ward & $87(35)$ & $5(10)$ & $82(41) * *$ \\
\hline Orthopaedic ward & $95(38)$ & $5(10)$ & $90(45)^{* *}$ \\
\hline ICU & $65(26)$ & $41(80)$ & $24(12)^{* *}$ \\
\hline Other & $5(2)$ & $0(0)$ & $5(2)$ \\
\hline
\end{tabular}

Values are number $(n)$ and percentage $(\%)$ in parenthesis, except for age and ISS score which are mean (SD)

ISS injury severity score, GCS Glasgow coma scale, MVA motor vehicle accident, $M B A$ motor bike accident, $I C U$ intensive care unit $* P<0.01$; ** $P<0.001, \chi^{2}$ test comparing patients who received tertiary survey versus those who did not

Of the 252 patients, $51(20 \%)$ had a formal tertiary survey (TS) performed during their hospital stay. The mean ISS of patients who had received a formal TS was higher than that of patients who did not have a TS performed (23.0 vs. $10.4, P<0.001)$. Only $50 \%$ of the severely injured (ISS $>15$ ) and $39 \%$ with an abnormal level of consciousness $(\mathrm{GCS}<15)$ had a TS performed during their ward admission. More TSs were performed in the ICU than in the general wards $(63 \%$ vs. $5 \%, P<0.001)$.

\section{Missed injuries}

Table 3 outlines the nine missed injuries in eight $(3.2 \%)$ patients. Of these, six injuries were detected in patients who had a TS. Two injuries were deemed clinically significant. Of these, one patient had a fractured proximal phalanx of the big toe (patient did not have TS) and one patient had a fractured calcaneus that was detected on TS. 
Table 3 Description of newly detected injuries (missed injuries), investigations, and management

\begin{tabular}{lll}
\hline & Area of injury & Further investigation and subsequent management \\
\hline Formal TS performed & & \\
Patient 1 & L hand & X-ray - NAD \\
Patient 2 & Tender R foot & X-ray - NAD \\
Patient 3 & L elbow & X-ray- NAD, orthopaedic consult: conservative management \\
& R shoulder & X-ray - NAD, orthopaedic consult: conservative management \\
Patient 4 & R knee & X-ray - NAD \\
Patient 5 & L ankle & X-ray - fractured calcaneus, orthopaedic consultation with \\
& & plaster immobilisation \\
No formal TS performed & & \\
Patient 6 & Left knee & Mobilisation \\
Patient 7 & L knee deformity & X-ray - NAD, orthopaedic consult: conservative management \\
Patient 8 & Toe & X-ray - fractured toe, patient self-discharged \\
\hline
\end{tabular}

$N A D$ no abnormality detected, $T S$ tertiary survey, $L$ left, $R$ right

Table 4 Documentation rates of vital signs

\begin{tabular}{llll}
\hline Vital signs & $\begin{array}{l}\text { Total } \\
(n=252)\end{array}$ & $\begin{array}{l}\text { Tertiary } \\
\text { survey } \\
\text { performed } \\
(n=51)\end{array}$ & $\begin{array}{l}\text { No tertiary } \\
\text { survey } \\
\text { performed } \\
(n=201)\end{array}$ \\
\hline $\begin{array}{l}\text { Glasgow coma score } \\
\text { documented }\end{array}$ & 24 & 61 & $15^{* *}$ \\
$\begin{array}{l}\text { Temperature documented } \\
\text { Blood pressure documented }\end{array}$ & 43 & 63 & $38^{*}$ \\
$\begin{array}{l}\text { Heart rate documented } \\
\text { Respiratory rate documented }\end{array}$ & 31 & 77 & $20^{* *}$ \\
$\begin{array}{l}\text { Oxygen saturations } \\
\text { documented }\end{array}$ & 31 & 80 & $17^{* *}$ \\
\hline
\end{tabular}

All values are percent $(\%)$

$* P<0.01$; ** $P<0.001$ based on $\chi^{2}$ test comparing patients who received a tertiary survey with those who did not

Tertiary survey documentation: vital signs

In the group without formal TS, vital signs were poorly documented, varying between $15 \%$ for respiratory rate to $43 \%$ for temperature. In the group of patients who did have a formal TS, these rates varied from $41 \%$ for respiratory rate to $80 \%$ for the heart rate (Table 4 ).

Tertiary survey documentation: physical examination

Overall, the documentation rate of the physical examination was poor, with $27 \%$ for both abdominal and chest examinations, $26 \%$ for the lower limbs, and $33 \%$ for the upper limbs. Other areas, as outlined in Table 5, were documented in less than $10 \%$ of all patients. In patients who did have a formal TS performed, these percentages were markedly higher, with $69 \%$ documenting the abdominal examination and 59\% the chest examination.
Upper- and lower-limb documentation occurred in 53 and $65 \%$ of patients, respectively.

Tertiary survey documentation: pathology and diagnostic imaging

Overall, the full blood count or haemoglobin was documented in $23 \%$ of patients, whereas this rate was $71 \%$ in the subgroup of patients who had a formal TS. Plain film review occurred in $14 \%$ of all patients and in $43 \%$ of patients who had a TS. Formal review by the radiology registrar or consultant occurred twice (Table 6).

Advanced imaging (CT, MRI, and ultrasound) review by a treating team member was documented in $13 \%$ of all patients and in $37 \%$ of patients who had a TS. There were provisional radiology reports of advanced imaging noted, but no documented review by a radiology registrar or consultant as a result of patient review (or TS) by the admitting team.

\section{Discussion}

A formal tertiary survey (either partial or complete depending on documentation) was performed for only $20 \%$ of all admitted trauma patients, and the missed injury rate was $3.2 \%$. This study found overall poor documentation rates of re-examination of the trauma patients after admission. The majority of tertiary survey components was poorly documented by the admitting team. Although documentation was better in the group that did receive a formal TS, a substantial proportion of this group did not have relevant TS components documented.

As expected, the more injured patients (ISS $>15$ ) were more likely to have a TS documented, although half of 
Table 5 Documentation rates of physical examination

\begin{tabular}{|c|c|c|c|}
\hline $\begin{array}{l}\text { Location of physical } \\
\text { exam }\end{array}$ & $\begin{array}{l}\text { Total } \\
(n=252)\end{array}$ & $\begin{array}{l}\text { Tertiary } \\
\text { survey } \\
\text { performed } \\
(n=51)\end{array}$ & $\begin{array}{l}\text { No } \\
\text { tertiary } \\
\text { survey } \\
\text { performed } \\
(n=201)\end{array}$ \\
\hline Scalp documented & 5 & 12 & $3 * *$ \\
\hline Face documented & 7 & 20 & $3 * * *$ \\
\hline Eyes documented & 16 & 52 & $7 * * *$ \\
\hline Ears documented & 0.4 & 2 & 0 \\
\hline Mouth documented & 2 & 6 & 1 \\
\hline Cranial nerves documented & 1 & 4 & 0.5 \\
\hline Neck documented & 6 & 17 & $3 * * *$ \\
\hline Trachea documented & 1 & 0 & 1 \\
\hline C-spine documented & 8 & 25 & $4 * * *$ \\
\hline $\begin{array}{l}\text { Chest (including ribs) } \\
\text { documented }\end{array}$ & 27 & 58 & $19 * * *$ \\
\hline Sternum documented & 6 & 18 & $3 * * *$ \\
\hline Shoulder/clavicle documented & 9 & 27 & $5 * * *$ \\
\hline ICC documented & 9 & 25 & $4 * * *$ \\
\hline ICC not applicable & 63 & 47 & $68 * *$ \\
\hline Abdomen documented & 28 & 69 & $17 * * *$ \\
\hline Pelvis documented & 7 & 27 & $2 * * *$ \\
\hline Genitalia documented & 2 & 7 & 0 \\
\hline Back documented & 3 & 12 & 1 \\
\hline $\mathrm{T}+\mathrm{L}$ spine documented & 4 & 14 & 2 \\
\hline Upper limb documented & 25 & 53 & $19 * * *$ \\
\hline Lower limb documented & 32 & 65 & $24 * * *$ \\
\hline Pulses documented & 6 & 12 & $4 *$ \\
\hline
\end{tabular}

All values are percent $(\%)$

$* P<0.05$; ** $P<0.01$; *** $P<0.001$ based on $\chi^{2}$ test comparing patients who received a tertiary survey with those who did not

these patients did not have a formal TS performed. We also found that formal TS performance and documentation rates were higher in patients who were admitted to the ICU compared to those of patients who were admitted to a surgical or orthopaedic ward (63 vs. 5\%). This may be due to a more holistic and structured approach to examination and documentation by the intensive care medical staff.

In our study, the missed injury rate was $3.2 \%$. This is low and consistent with that of previous retrospective studies of trauma admissions with similar ISS (1.2-4\%), albeit in hospitals with a trauma service [3-5, 9, 10]. It is likely that our study underestimates the true missed injury rate since we did not follow up patients after hospital discharge. Enderson et al. [1] found that the missed injury incidence changed from $2 \%$ when studied retrospectively to $9 \%$ when studied prospectively in the same institution. Our current missed injury rate will serve as a baseline comparison for future studies at our institution. The low missed injury rate seems paradoxical as this study
Table 6 Documentation rates of pathology and radiology

\begin{tabular}{|c|c|c|c|}
\hline $\begin{array}{l}\text { Pathology or plain } \\
\text { radiology }\end{array}$ & $\begin{array}{l}\text { Total } \\
(n=252)\end{array}$ & $\begin{array}{l}\text { Tertiary } \\
\text { survey } \\
\text { performed } \\
(n=51)\end{array}$ & $\begin{array}{l}\text { No tertiary } \\
\text { survey } \\
\text { performed } \\
(n=201)\end{array}$ \\
\hline FBC documented & 23 & 71 & $10 * * *$ \\
\hline COAGS documented & 11 & 39 & $4 * * *$ \\
\hline UELFTs documented & 17 & 55 & $7 * * *$ \\
\hline Plain X-ray documented & 14 & 43 & $7 * * *$ \\
\hline \multicolumn{4}{|l|}{ Plain X-ray reviewed by } \\
\hline Intern & 0.4 & 2 & 0 \\
\hline Resident & 3 & 6 & 3 \\
\hline Registrar & 6 & 22 & $3 * * *$ \\
\hline Consultant & 3 & 10 & 2 \\
\hline Radiology registrar & 0.4 & 2 & 0 \\
\hline Radiology consultant & 0.4 & 0 & 0.5 \\
\hline Not applicable & 85 & 57 & $92 * * *$ \\
\hline \multicolumn{4}{|l|}{ CT/MRI/USS reviewed by } \\
\hline Intern & 0.4 & 2 & $0(0)$ \\
\hline Resident & 2 & 4 & $3(1.5)$ \\
\hline Registrar & 8 & 2 & $6(3)^{* * *}$ \\
\hline Consultant & 2 & $5(10)$ & $0(0)$ \\
\hline Radiology registrar & 2 & $0(0)$ & $4(2)$ \\
\hline Radiology consultant & 0 & 0 & 0 \\
\hline Not applicable & 86 & $29(58)$ & $183(93) * * *$ \\
\hline
\end{tabular}

Values are percent $(\%)$

$F B C$ full blood count, COAGS coagulation studies, UELFTs electrolytes, renal and liver function tests, $n$ number, $C T$ computerized tomography scan, MRI magnetic resonance imaging scan, USS ultrasound scan

highlights the poor performance and documentation of tertiary surveys, and one may have expected more missed injuries as a result. It is not possible to determine how many patients in our study were discharged with missed injuries. Caution is required when interpreting missed injury rates as there are inconsistent definitions of this term in the literature $[1-6,10-12,18]$. This inconsistency of the definition of "missed injury" has been highlighted by two recent review articles on missed injuries $[19,20]$ and should guide interpretation, although we used a common definition, i.e., "any injury identified after primary and secondary survey or initial investigations in the operating room" $[6,10-12]$.

Our low missed injury rate may be explained by the fact that (most) conscious patients could indicate all their injuries. A second explanation is that tertiary surveys may have been performed but not documented. It is possible that only new findings on patient re-examination, blood tests, or diagnostic imaging were documented. Although this may be understandable in the face of time, staffing, and resource pressures, incomplete documentation may have 
both medical and medicolegal implications. It remains important to document important negative findings, or the absence of so-called "red flags" on re-examination. A final explanation for the low rates of missed injuries and TS documentation may be the absence of a dedicated trauma service in our institution. The admitting team may have reviewed the patients with a disproportionate focus on the primary reason for their admission, potentially missing injuries in other body systems and discharging patients with missed injuries.

An interesting finding was that as a result of repeat examination by the admitting team, additional diagnostic imaging review by a radiologist occurred only twice. Both times this involved plain film imaging and no documented radiologist review of advanced imaging occurred. Prospective studies have demonstrated more accurate and earlier detection of missed injuries when diagnostic imaging is reviewed by a radiologist $[8,21]$. One prospective study of 432 trauma patients showed that $9 \%$ had missed injuries detected the following day by a radiology consultant, of which $40 \%$ were clinically significant fractures [21].

Previous studies have suggested that there are different types of human error when classifying missed injuries [20, 22]. The lack of review of diagnostic imaging, as noted in our study, can be classed as either a delay in requesting imaging or consultation that may lead to a delay in diagnosis (or missed injury), or an error in diagnosis. A trauma service can be part of a system where recognized error patterns can be prevented [22]. Two recent studies suggest that inclusive trauma systems reduce trauma-related mortality [23, 24], and implementing a dedicated trauma service could be a first appropriate step for regional hospitals to achieve such a system.

This study has several limitations. First, it is a retrospective study that limits data collection to what is available in the medical records, which probably resulted in an underestimation of the missed injury rate [1]. Second, this study is subject to all limitations associated with medical record review, such as chart ambiguity, omission, illegibility, and data entry error. We minimized this by crosschecking our data with the Queensland Trauma Registry, which accesses electronic hospital administrative databases in conjunction with the medical record. Furthermore, our recruitment criteria included patients with a fractured neck of femur under the age of 65 , considering the mechanism required to sustain this injury in a younger person. Although this group of patients has traditionally not been included in studies on multiply injured patients, only four patients with this diagnosis were included, therefore limiting the impact of their inclusion on the study outcomes. Finally, although we used a reasonable cohort size, this study covered a single site and results may not be reflective of other facilities.

\section{Conclusions}

Currently in our designated trauma-receiving hospital without a dedicated trauma service, a tertiary survey occurs for only $20 \%$ of all trauma admissions. Despite this suboptimal practice, the missed injury rate was $3.2 \%$, which is comparable to other retrospective studies, although it is likely an underestimation. There is a role for a more formalized review of diagnostic imaging, potentially leading to more accurate clinical correlation and fewer missed injuries. This study highlights areas of trauma care that can be improved, which may be facilitated by implementing a dedicated trauma service. Meanwhile, we have commenced data collection for a larger, prospective study with a 6-month follow-up to more accurately assess the missed injury rate and associated morbidity after patients are discharged. We plan to implement a formal, institutional tertiary survey for all trauma admissions in our setting to improve documentation practice.

Acknowledgments This study was supported by a grant from the Queensland Emergency Medicine Research Foundation (Grant QEMRF-EMSS-2008-008). We acknowledge Jacelle Lang, Kathy Harvey, and Christina Jennekens from the Queensland Trauma Registry for their support and data, Chris Heenan from the Gold Coast Hospital for data collection support, Associate Professor Marie Cooke from Griffith University for her early involvement, and Professor Chris Del Mar from Bond University for proof-reading the manuscript.

\section{References}

1. Enderson BL, Reath DB, Meadors J et al (1990) The tertiary trauma survey: a prospective study of missed injury. J Trauma 30:666-670

2. Frawley PA (1993) Missed injuries in the multiply traumatized. Aust N Z J Surg 63:935-939

3. Aaland MO, Smith K (1996) Delayed diagnosis in a rural trauma center. Surgery 120:774-779

4. Robertson R, Mattox R, Collins T et al (1996) Missed injuries in a rural trauma center. Am J Surg 172:564-567

5. Furnival RA, Woodward GA, Schunk JE (1996) Delayed diagnosis of injury in pediatric trauma. Pediatrics 98:56-62

6. Janjua KJ, Sugrue M, Deane SA (1998) Prospective evaluation of early missed injuries and the role of tertiary trauma survey. J Trauma 44:1000-1007

7. Buduhan G, McRitchie, Donna I (2000) Missed injuries in patients with multiple trauma. J Trauma 49:600-605

8. Houshian S, Larsen MS, Holm C (2002) Missed injuries in a level I trauma center. J Trauma 52:715-719

9. Biffl WL, Harrington DT, Cioffi WG (2003) Implementation of a tertiary trauma survey decreases missed injuries. J Trauma 54:38-44

10. Vles WJ, Veen EJ, Roukema JA et al (2003) Consequences of delayed diagnoses in trauma patients: a prospective study. J Am Coll Surg 197:596-602

11. Soundappan SV, Holland AJ, Cass DT (2004) Role of an extended tertiary survey in detecting missed injuries in children. J Trauma 57:114-118 
12. Brooks A, Holroyd B, Riley B (2004) Missed injury in major trauma patients. Injury 35:407-410

13. Albrektsen SB, Thomsen JL (1989) Detection of injuries in traumatic deaths: the significance of medico-legal autopsy. Forensic Sci Int 42:135-143

14. Stothert JC Jr, Gbaanador GB, Herndon DN (1990) The role of autopsy in death resulting from trauma. J Trauma 30:10211026

15. Royal Australasian College of Surgeons (2009) Trauma Verification. Benchmarking Trauma Care. Model Resource Criteria for Level I, II, III and IV Trauma Services in Australasia, August 2009. http://www.surgeons.org/Content/NavigationMenu/Fellowship andStandards/FellowshipServices/Trauma/2009-08-04_MRC_for_ website.pdf. Accessed 20 Oct 2010

16. Australasian College of Emergency Medicine Policy on Australian Triage scale. http://www.acem.org.au/media/policies_and_ guidelines/P06_Aust_Triage_Scale_Nov_2000.pdf. Accessed 28 Oct 2010

17. Baker SP, O’Neill B, Haddon W Jr, Long WB (1974) The injury severity score: a method for describing patients with multiple injuries and evaluating emergency care. J Trauma 14:187-196
18. Stephan PJ, McCarley MC, O'Keefe GE et al (2002) 23-hour observation solely for identification of missed injuries after trauma: is it justified? J Trauma 53:895-900

19. Pfeifer R, Pape HC (2008) Missed injuries in trauma patients: a literature review. Patient Saf Surg 2:20

20. Thomson CB, Greaves I (2008) Missed injury and the tertiary trauma survey. Injury 39:107-114

21. Hoff WS, Sicoutris CP, Lee SY et al (2004) Formalized radiology rounds: the final component of the tertiary survey. J Trauma $56: 291-295$

22. Clarke DL, Gouveia J, Thomson SR, Muckart DJJ (2008) Applying modern error theory to the problem of missed injuries in trauma. World J Surg 32:1176-1182. doi:10.1007/s00268008-9543-7

23. Moore L, Hanley JA, Turgeon AF, Lavoie A (2010) Evaluation of the long-term trend in mortality from injury in a mature inclusive trauma system. World J Surg 34:2069-2075. doi:10.1007/s00268-010-0588-Z

24. Tinkoff GH, Reed JF, Megargel R, Alexander EL, Murphy S, Jones MS (2010) Delaware's inclusive trauma system: impact on mortality. J Trauma 69:245-252 